\title{
HUBUNGAN ANTARA MINAT BELAJAR DAN HASIL BELAJAR BAHASA INDONESIA PADA MURID KELAS V SDN 4 TG BATU KECAMATAN BANGGAE KABUPATEN MAJENE
}

\author{
Abdan Syakur. \\ Pendidikan Guru Sekolah Dasar, Fakultas Keguruan dan Ilmu Pendidikan \\ Universitas Muhammadiyah Makassar \\ Iqramsyar34@gmail.com
}

\begin{abstract}
ABSTRAK
Masalah utama dalam penelitian ini adalah apakah ada Hubungan yang Signifikan antara Minat Belajar dan Hasil Belajar Bahasa Indonesia pada Murid Kelas V SDN 4 Tg Batu Kecamatan Banggae Kabupaten Majene. Tujuan penelitian adalah untuk mengetahui seberapa besar Hubungan antara Minat Belajar dan Hasil Belajar Bahasa Indonesia pada Murid Kelas V SDN 4 Tg Batu Kecamatan Banggae Kabupaten Majene, dengan memilih 32 orang murid sebagai sampel yang terdiri dari 2 kelas yaitu kelas $\mathrm{Va}$ dan $\mathrm{Vb}$, sedangkan pengumpulan data menggunakan teknik wawancara, kuisioner, dan dokumentasi. Hasil analisis data menunjukkan bahwa Hubungan Minat Belajar Bahasa Indonesia (X), dan Hasil Belajar Bahasa Indonesia (Y) yang ditunjukkan dengan nilai koefisien korelasi sebesar 0,643. Sedangkan untuk uji signifikan uji $r$ diperoleh bahwa $r_{\text {hitung }}$ yang diperoleh adalah lebih besar dari $r_{\text {tabel }}$ $(0,643 \geq 0,361)$, pada taraf signifikan $5 \%$. Sehingga terlihat bahwa nilai $r_{h i t u n g}$ lebih besar dari pada nilai $r_{\text {tabel }}$, maka hipotesis dalam penelitian ini "diterima" dan Terdapat Hubungan yang signifikan antara Minat Belajar dengan Hasil Belajar Murid dalam Mata Pelajaran Bahasa Indonesia pada Murid Kelas V SDN 4 Tg Batu Kecamatan Banggae Kabupaten Majene.
\end{abstract}

Kata kunci: Hubungan Minat Belajar; Hasil Belajar 


\section{PENDAHULUAN}

Dalam Kurikulum Tingkat Satuan Pendidikan (KTSP) menghendaki agar guru dapat merancang dan menerapkan model pembelajaran yang memungkinkan murid merasa senang dan tidak bosan terhadap materi yang diajarkan sehingga hasil belajarnya dapat meningkat. Atau dengan kata lain guru harus menempuh proses kreatif agar murid berminat dalam mengikuti pembelajaran atau meminati materi pelajarannya.

Hal ini sangat relevan dengan prinsip pelaksanaan KTSP yaitu: (PAKEM). (Pusat Kurikulum, 2006: 23) "Upaya memandirikan peserta didik untuk belajar, bekerja sama, dan menilai diri sendiri diutamakan agar peserta didik mampu membangun kemampuan, pemahaman, dan pengetahuannya. Peningkatan potensi, kecerdasan, dan minat peserta didik perlu terus menerus diupayakan. Penilaian berkelanjutan dan komprehensif menjadi sangat penting dalam rangka pencapaian upaya tersebut. Penyajiannya disesuaikan dengan tahap-tahap perkembangan peserta didik melalui pembelajaran aktif, kreatif, efektif, dan menyenangkan".

Sehubungan dengan masukan tersebut, Sardiman (2001: 132) juga berpendapat bahwa terdapat tiga faktor-faktor yang mempengaruhi hasil belajar murid. Ketiga faktor tersebut adalah: “(1) faktor yang bersifat internal yaitu, semua faktor yang ada dalam diri itu sendiri (minat, bakat, keseriusan); (2) faktor yang bersifat eksternal yaitu faktor berasal dari luar diri murid (lingkungan, orang tua, ekonomi dan politik); dan (3) faktor fisik (jasmani) yaitu faktor yang berkaitan dengan kesehatan badan dan kesempurnaan fisik dan mental".

Mencermati konsep di atas, maka dapat dinyatakan bahwa minat belajar atau minat terhadap materi atau hal yang berkaitan dengan mata pelajaran merupakan unsur penting dalam pembelajaran. Oleh karena itu, seluruh komponen sekolah wajib menumbuhkan minat belajar murid dengan membenahi berbagai sistem yang berpengaruh.

Demikian juga halnya pada SDN 4 Tg Batu Kecamatan Banggae Kabupaten Majene, yang menjadi faktor utama tercapainya hasil belajar murid salah satunya adalah minat belajar, yang sering menjadi kendala dalam tercapainya pembelajaran khusunya pada mata pelajaran bahasa Indonesia.

Dalam dunia pendidikan di sekolah, minat memegang peran penting dalam belajar. Karena minat berkaitan dengan motivasi, minat merupakan dorongan dalam diri seseorang atau faktor yang menimbulkan perhatian secara selektif yang 
menyebabkan dipilihnya suatu objek atau kegiatan yang menguntungkan, menyenangkan yang lama kelamaan akan mendatangkan kepuasan.

Oleh karena itu antara dorongan, Perhatian dan rasa senang pada suatu kegiatan saling berkaitan dengan faktor yang menimbulkan minat. Apabila faktorfaktor yang menimbulkan minat pada suatu kegiatan rendah maka dapat menyebabkan minat seseorang itu rendah. Minat yang rendah dapat menimbulkan rasa bosan terhadap suatu kegiatan. Apabila ini terjadi pada minat belajar Bahasa Indonesia maka akan berdampak pada kesulitan belajar seseorang tersebut.

Di sekolah dasar mata pelajaran yang diajarkan merupakan dasar dari semua mata pelajaran untuk menjadi dasar pengetahuan di jenjang pendidikan selanjutnya yang lebih tinggi. Mata pelajaran bahasa Indonesia termasuk mata pelajaran yang materinya cukup sulit dipahami. Hal ini bukan saja karena kompleks, tetapi juga karena banyak istilah yang perlu pencermatan mendalam.

Minat belajar murid sangat mempengaruhi hasil belajar murid agar dapat memahami dengan baik. Dengan minat belajar yang tinggi maka dengan mudah murid dapat memahami pelajaran dengan mudah walaupun materi yang diajarkan cukup sulit. Dalam hal ini, minat belajar murid sangat berpengaruh pada hasil belajar murid.

Berdasarkan uraian di atas, maka peneliti tertarik untuk melakukan penelitian mengenai "Hubungan antara Minat Belajar dan Hasil belajar bahasa Indonesia. Hasil penelitian ini diharapkan dapat bermanfaat terutama sebagai bahan masukan kepada guru untuk menumbuhkan minat belajar murid terhadap mata pelajaran Bahasa Indonesia di sekolah dasar.

Berdasarkan uraian di atas rumusan masalah dalam penelitian ini adalah pakah terdapat hubungan antara minat belajar dan hasil belajar bahasa Indonesia pada murid kelas V SDN 4 Tg Batu Kecamatan Banggae Kabupaten Majene?. Tujuan penelitian ini adalah mengetahui Untuk mengetahui hubungan antara minat belajar dan hasil belajar bahasa Indonesia pada murid kelas V SDN 4 Tg Batu Kecamatan Banggae Kabupaten Majene.

\section{Pengertian Belajar}

Menurut (Hamalik, 2008:154)) mengemukakan bahwa belajar merupakan dalam perbuatan melalui aktifitas, praktek dan pengalaman. Lebih lanjut Hamalik (2008:155) mendefinisikan belajar ialah terjadinya perubahan presepsi dan perilaku, termaksud juga perbaikan perilaku, misalnya pemuasan kebutuhan masyarakat dan 
pribadi secara lebih lengkap. Pengalaman itu sendiri pada dasarnya adalah interaksi antar individu dengan lingkungannya. Dengan adanya proses interaksi antara lain dapat tercipta dari guru dan murid.

Menurut Winkel, W.S $(2009,58)$ belajar merupakan kegiatan mental yang tidak dapat disaksikan dari luar. Sedanfkan menurut Ormond (Ratumanan, 2004: 2) mendeksripsikan adanya dua defenisi belajar yang berbeda. Definisi pertama menyatakan bahwa: belajar merupakan perilaku yang relative permanen karena pengalaman. Definisi kedua menyatakn bahwa: perubahan yang relative permanent karena pengalaman.

Menurut Gagne (Ratumanan, 2004: 70), belajar merupakan sesuatu yang terjadi didalam benak seseorang, di dalam otaknya. Belajar juga merupakan proses yang memungkinkan manusia memodifikasi tingkah laku secara permanent, sehingga modifikasi yang sama tidak akan terjadi lagi pada situasi yang baru.

Dari uraian di atas maka dapat diambil kesimpulan bahwa belajar yaitu suatu proses untuk mencapai suatu tujuan yaitu perubahan tingkah laku kearah yang lebih baik. Perubahan tingkah laku tersebut berlaku dalam waktu relative sama dan disertai perubahan pada diri orang tersebut sehingga orang itu tidak mampu menjadi mampu mengerjakannya.

\section{Hasil Belajar}

Hasil belajar adalah kemampuan yang dimiliki murid setelah ia menerima pengalaman belajarnya. Hasil belajar mempunyai peranan penting dalam proses pembelajaran. Proses penilaian terhadap hasil belajar dapat memberikan informasi kepada guru tentang kemajuan murid dalam upaya mencapai tujuan-tujuan belajarnya melalui kegiatan belajar.

Menurut (Hamalik, 2008:20) Hasil belajar merupakan hal yang dapat dipandang dari dua sisi yaitu sisi murid dan dari sisi guru. Dari sisi murid, hasil belajar merupakan tingkat perkembangan mental yang lebih baik bila dibandingkan pada saat sebelum belajar.

Hasil belajar sangat ditentukan oleh kapasitas belajar yang dilakukan murid. Kita ketahui bahwa belajar merupakan aktivitas, memerlukan interaksi, latihan, lingkungan dengan selang waktu tertentu, selama itu akan nampak perubahanperubahan pada diri individu yang belajar. Hasil inilah yang disebut sebagai hasil belajar. 
Berdasarkan uraian di atas maka dapat disimpulkan bahwa hasil belajar bahasa Indonesia adalah nilai yang dicapai oleh murid melalui evaluasi materi pelajaran bahasa Indonesia yang diberikan oleh guru dalam hal ini setelah proses belajar mengajar berlangsung.

\section{Pengertian Minat Belajar}

Menurut Slameto (2010:182) minat adalah minat adalah suatu rasa lebih suka dan rasa keterikatan pada suatu hal atau aktivitas, tanpa ada yang menyuruh. Minat pada dasarnya adalah penerimaan akan suatu hubungan antara diri sendiri dengan sesuatu di luar diri. Semakin kuat atau dekat hubungan tersebut, semakin besar.

William James dalam Usman (2002: 27) mengemukakan bahwa minat murid merupakan faktor utama yang menentukan derajat keaktifan belajar murid. Jadi aktif merupakan faktor yang menentukan keterlibatan murid secara aktif dalam belajar. Menurut safari (2003) minat belajar adalah pilihan dalam melakukan kegiatan dan dapat membangkitkan gairah seseorang untuk memenuhi kesediaannya yang dapat diukur melalui kesukacitaan, ketertarikan, perhatian dan keterlibatan.

Berdasarkan uraian di atas, dapat disimpulkan bahwa minat belajar adalah kecendrungan yang timbul dari dalam diri seseorang yang akan menimbulkan rasa suka atau ketertarikan terhadap suatu objek.

\section{METODE PENELITIAN}

Penelitian ini adalah penelitian metode survei "mengumpulkan data sebanyaknya mengenai faktor yang merupakan pendukung terhadap kualitas belajar mengajar" dengan pendekatan korelasional yaitu meneliti tentang hubungan antara dua hal atau lebih" selanjutnya dikorelasikan antara variabel bebas dengan variabel terikat.

Populasi dalam penelitian ini adalah seluruh Murid SDN 4 Tg Batu Kecamatan Banggae Kabupaten Majene sebanyak 220 murid.. Pada penelitian ini, yang menjadi sampel adalah 1/2 dari jumlah keseluruhan murid kelas Va dan Vb dengan jumlah 32 murid. Instrumen pada penelitian ini menggunakan angket, dokumentasi, wawancara dan observasi. Data yang diperoleh dianalisis dengan menggunakan teknik analisis statistik deskriptif dan analisis statistik korelasi Product moment untuk pengujian hipotesis, yang sebelumnya didahului dengan uji persyaratan analisis uji normalitas data. 


\section{HASIL PENELITIAN DAN PEMBAHASAN}

Hasil analisis deskriptif yang berkaitan dengan skor variabel minat belajar Bahasa Indonesia murid.

Tabel 1. Statistik Deskriptif Skor Minat Belajar Bahasa Indonesia

\begin{tabular}{|l|c|}
\hline \multicolumn{1}{|c|}{ Statistik } & Nilai Statistik \\
\hline Ukuran Sampel & 32 \\
\hline Skor Tertinggi & 95 \\
\hline Skor Terendah & 69 \\
\hline Rentang Skor & 26 \\
\hline Skor rata-rata & 80,9 \\
\hline Standar Deviasi & 81,8 \\
\hline Jumlah (Sum) & 2589 \\
\hline
\end{tabular}

Pada tabel 1. menunjukkan bahwa skor rata-rata minat belajar Bahasa Indonesia adalah 80,9 dari skor total yang mencapai 100 atau secara kualitatif dikategorikan tinggi, skor tertinggi yang dicapai 95, skor terendah 69 dengan standar deviasi 81,8 dan rentang skornya 26 . Jadi, berdasarkan uraian tersebut dapat disimpulkan bahwa minat belajar murid SDN $4 \mathrm{Tg}$ Batu Kecamatan Banggae Kabupaten Majene dikategorikan tinggi dalam mengikuti pelajaran Bahasa Indonesia.

Hasil distribusi frekuensi minat belajar Bahasa Indonesia murid SDN 4 Tg Batu Kecamatan Banggae Kabupaten Majene, maka diklasifikasikan atas lima kategori yaitu, Sangat tinggi, Tinggi, Sedang, Rendah dan Sangat rendah. Terdapat pada tabel berikut :

Tabel 2. Distribusi Frekuensi Minat Belajar Bahasa Indonesia SD Inpres Tello Baru I/II

Kota Makassar

\begin{tabular}{|c|c|c|c|}
\hline Interval Nilai & Minat Belajar & Frekuensi & Presentase $\%$ \\
\hline $88-100$ & Sangat tinggi & 5 & $15,62 \%$ \\
\hline $83-87$ & Tinggi & 9 & $28,12 \%$ \\
\hline
\end{tabular}




\begin{tabular}{|c|c|c|c|}
\hline $78-82$ & Sedang & 7 & $21,88 \%$ \\
\hline $73-77$ & Rendah & 8 & $25 \%$ \\
\hline $68-72$ & Sangat rendah & 3 & $9,38 \%$ \\
\hline \multicolumn{2}{|c|}{ Jumlah } & 32 & 100 \\
\hline
\end{tabular}

Berdasarkan tabel 2 di atas di peroleh distribusi frekuensi minat belajar Bahasa Indonesia murid kelas V SDN 4 Tg Batu Kecamatan Banggae Kabupaten Majene yaitu sangat tinggi berada pada interval 88 - 100 dengan frekuensi murid 5 (15,62\%) , tinggi dengan jarak interval 83 - 87 dengan frekuensi murid 9 (28,12\%), sedang dengan jarak interval 78 - 82 dengan frekuensi murid 7 (21,88\%), rendah dengan jarak interval 73 - 77 dengan frekuensi murid 8 (25\%) dan sangat rendah dengan jarak interval 68 - 72 dengan frekuensi 3 (9,83\%). Ini berarti dari hasil distribusi frekuensi nilai minat belajar murid berada pada kategori tinggi yang memiliki frekuensi terbanyak dari nilai belajar Bahasa Indonesia murid.

\section{Hasil belajar Bahasa Indonesia}

Hasil analisis deskriptif yang berkaitan dengan skor variabel hasil belajar Bahasa Indonesia murid.

Tabel 3. Statistik Deskriptif Skor Hasil Belajar Bahasa Indonesia

\begin{tabular}{|l|c|}
\hline \multicolumn{1}{|c|}{ Statistik } & Deskriptif \\
\hline Ukuran Sampel & 32 \\
\hline Skor Tertinggi & 92 \\
\hline Skor Terendah & 71 \\
\hline Rentang Skor & 21 \\
\hline Skor Rata-rata & 80,7 \\
\hline Standar Deviasi & 80,9 \\
\hline Jumlah (Sum) & 2583 \\
\hline
\end{tabular}

Pada tabel 3. menunjukkan bahwa skor rata-rata hasil belajar Bahasa Indonesia adalah 80,7 dari skor total yang mencapai 100 atau secara kualitatif dikategorikan 
tinggi dan skor tertinggi yang dicapai 92, skor terendah 71 dengan standar deviasi 80,9 dan rentang skornya 21 . Jadi, berdasarkan uraian tersebut dapat disimpulkan bahwa hasil belajar murid Bahasa Indonesia murid SDN 4 Tg Batu Kecamatan Banggae Kabupaten Majene dikategorikan tinggi dalam mengikuti pelajaran Bahasa Indonesia.

Hasil distribusi frekuensi hasil belajar Bahasa Indonesia Murid SDN 4 Tg Batu Kecamatan Banggae Kabupaten Majene, maka diklasifikasikan atas lima kategori yaitu, Sangat Tinggi, Tinggi, Sedang, Rendah dan Sangat rendah. Terdapat pada tabel berikut

Tabel 4. Distribusi Frekuensi Hasil Belajar Bahasa Indonesia SDN 4 Tg Batu Kecamatan Banggae Kabupaten Majene.

\begin{tabular}{|c|c|c|c|}
\hline Interval Nilai & Interprestasi & Frekuensi & Presentase\% \\
\hline $86-100$ & Sangat tinggi & 8 & $25 \%$ \\
\hline $82-85$ & Tinggi & 7 & $21,88 \%$ \\
\hline $78-81$ & Sedang & 8 & $25 \%$ \\
\hline $74-77$ & Rendah & 1 & $3,12 \%$ \\
\hline $70-73$ & Sangat rendah & 8 & $25 \%$ \\
\hline \multicolumn{2}{|r|}{ Jumlah } & 32 & 100 \\
\hline
\end{tabular}

Berdasarkan tabel 4 di atas di peroleh distribusi frekuensi hasil belajar Bahasa Indonesia murid SDN 4 Tg Batu Kecamatan Banggae Kabupaten Majene yang dijadikan sampel dalam penelitian yaitu sangat tinggi berada pada interval 86 - 100 dengan frekuensi murid 8 (25\%), tinggi dengan jarak interval 82 - 85 dengan frekuensi murid 7 (21,88 \%) , sedang dengan jarak interval 78 - 81 dengan frekuensi murid 8 (25\%) , rendah dengan jarak interval 74 - 77 dengan frekuensi murid 1 (3,12 \%) dan sangat rendah dengan jarak interval 70 - 73 dengan frekuensi 8 (25\%). Dengan demikian dapat disumpulkan bahwa hasil belajar Bahasa Indonesia murid SD Inpres Tello Baru I/II dalam kategori baik.

\section{Pengujian Hipotesis}

Data untuk penghitungan kofisien korelasi yang menyangkut hubungan antara minat belajar Bahasa Indonesia murid adalah variabel $(\mathrm{X})$ dan hasil belajar Bahasa Indonesia murid adalah variabel $(\mathrm{Y})$ antara lain jumlah sampel $(\mathrm{N})$, Jumlah skor $\mathrm{X}\left(\sum \mathrm{X}\right)$ 
jumlah kuadrat skor $\mathrm{X}\left(\sum \mathrm{X}^{2}\right)$, jumlah skor $\mathrm{Y}\left(\sum \mathrm{Y}\right)$, jumlah kuadrat skor $\mathrm{Y}\left(\sum \mathrm{Y}^{2}\right)$ dan Jumlah perkalian antara skor X dan $\mathrm{Y}(\Sigma \mathrm{XY})$.

Analisis korelasi adalah analisis keeratan hubungan antara dua variabel sehingga hasil analisis ini sebagai salah satu metode untuk menguji hipotesis $(\mathrm{H})$ maka terlebih dahulu hipotesis penelitian ( $\mathrm{Ha}$ ) atau hipotesis alternative di ubah menjadi hipotesis nol (Ho) yang menyatakan sebagai berikut: "Tidak ada Hubungan yang signifikan antara minat belajar dengan hasil belajar Bahasa Indonesia Murid kelas V SDN 4 Tg Batu Kecamatan Banggae Kabupaten Majene"

Tabel 5. Data Hasil Kerja Hubungan antara Minat Belajar dengan Hasil

Belajar Bahasa Indonesia murid kelas V SDN 4 Tg Batu Kecamatan

Banggae Kabupaten Majene

\begin{tabular}{|c|c|c|c|c|c|c|}
\hline $\begin{array}{c}\text { Kode } \\
\text { Sampel }\end{array}$ & Kelas & $\mathbf{X}$ & $\mathbf{Y}$ & $\mathrm{X}^{2}$ & $\mathbf{Y}^{2}$ & XY \\
\hline 1 & $\mathrm{Va}$ & 78 & 73 & 6084 & 5329 & 5694 \\
\hline 2 & $\mathrm{Va}$ & 82 & 87 & 6724 & 7569 & 7134 \\
\hline 3 & $\mathrm{Va}$ & 83 & 72 & 6889 & 5184 & 5976 \\
\hline 4 & $\mathrm{Va}$ & 88 & 73 & 7744 & 5329 & 6424 \\
\hline 5 & $\mathrm{Va}$ & 88 & 90 & 7744 & 8100 & 7920 \\
\hline 6 & $\mathrm{Va}$ & 71 & 73 & 5041 & 5329 & 5183 \\
\hline 7 & $\mathrm{Va}$ & 79 & 81 & 6241 & 6561 & 6399 \\
\hline 8 & $\mathrm{Va}$ & 73 & 71 & 5329 & 5041 & 5183 \\
\hline 9 & $\mathrm{Va}$ & 87 & 90 & 7569 & 8100 & 7830 \\
\hline 10 & $\mathrm{Va}$ & 89 & 82 & 7921 & 6724 & 7298 \\
\hline 11 & $\mathrm{Va}$ & 76 & 80 & 5776 & 6400 & 6080 \\
\hline 12 & $\mathrm{Va}$ & 82 & 79 & 6724 & 6241 & 6478 \\
\hline 13 & $\mathrm{Va}$ & 76 & 84 & 5776 & 7056 & 6384 \\
\hline 14 & $\mathrm{Va}$ & 75 & 79 & 5626 & 6241 & 5925 \\
\hline 15 & $\mathrm{Va}$ & 86 & 90 & 7396 & 8100 & 7740 \\
\hline 16 & $\mathrm{Va}$ & 79 & 81 & 6241 & 6561 & 6399 \\
\hline 17 & $\mathrm{Vb}$ & 95 & 82 & 9025 & 6724 & 7790 \\
\hline 18 & $\mathrm{Vb}$ & 78 & 81 & 6084 & 6561 & 6318 \\
\hline 19 & $\mathrm{Vb}$ & 91 & 90 & 8281 & 8100 & 8190 \\
\hline
\end{tabular}




\begin{tabular}{|c|c|c|c|c|c|c|}
\hline 20 & $\mathrm{Vb}$ & 91 & 92 & 8281 & 8464 & 8372 \\
\hline 21 & $\mathrm{Vb}$ & 78 & 81 & 6084 & 6561 & 6318 \\
\hline 22 & $\mathrm{Vb}$ & 73 & 72 & 5329 & 5184 & 5256 \\
\hline 23 & $\mathrm{Vb}$ & 85 & 82 & 7225 & 6724 & 6970 \\
\hline 24 & $\mathrm{Vb}$ & 86 & 79 & 7396 & 6241 & 6794 \\
\hline 25 & $\mathrm{Vb}$ & 75 & 74 & 5625 & 5476 & 5550 \\
\hline 26 & $\mathrm{Vb}$ & 88 & 90 & 7744 & 8100 & 7920 \\
\hline 27 & $\mathrm{Vb}$ & 74 & 79 & 5476 & 6241 & 5846 \\
\hline 28 & $\mathrm{Vb}$ & 69 & 72 & 4761 & 5184 & 4968 \\
\hline 29 & $\mathrm{Vb}$ & 74 & 80 & 5476 & 6400 & 5920 \\
\hline 30 & $\mathrm{Vb}$ & 71 & 72 & 5041 & 5184 & 5112 \\
\hline 31 & $\mathrm{Vb}$ & 81 & 89 & 6561 & 7921 & 7298 \\
\hline 32 & $\mathrm{Vb}$ & 88 & 83 & 7744 & 6889 & 6391 \\
\hline & & $\begin{array}{l}\sum X \\
=2589\end{array}$ & $\begin{array}{l}\sum Y \\
=2583\end{array}$ & $\begin{array}{l}\sum X^{2} \\
=210958\end{array}$ & $\begin{array}{l}\sum Y^{2} \\
=209819\end{array}$ & $\begin{array}{l}\sum X Y \\
=209884\end{array}$ \\
\hline
\end{tabular}

Berdasarkan hasil perhitungan yang terdapat pada table 5. dapat diketahui sebagai berikut :

$N \quad: \quad 32$

$\sum X \quad: \quad 2589$

$\sum Y: 2583$

$\sum X^{2}: \quad 210958$

$\sum Y^{2}: 209819$

$\sum X Y: 209884$

Selanjutnya, menggunakan rumus Product Moment untuk uji hipotesis dengan koefisien korelasi ( $r$ ) . Perhitungan selengkapnya sebagai berikut :

$$
\begin{aligned}
\mathrm{R}_{\mathrm{xy}}= & \frac{\mathrm{n} \sum \mathrm{XY}-\left(\sum \mathrm{X}\right)\left(\sum \mathrm{Y}\right)}{\sqrt{\mathrm{n} \sum \mathrm{X}^{2}-\left(\sum \mathrm{X}\right)^{2}} \sqrt{\mathrm{n} \sum \mathrm{Y}^{2}-\left(\sum \mathrm{Y}\right)^{2}}} \\
= & \frac{32 \times 209884-(2589)(2583)}{\sqrt{32 \times 210958-6702921} \sqrt{32 \times 209819-6671889}} \\
& =\frac{6716288-6687387}{\sqrt{(47735)} \sqrt{(42319)}}
\end{aligned}
$$




$$
\begin{aligned}
& =\frac{28901}{\sqrt{2020097465}} \\
& =\frac{28901}{44945} \\
& =0,643
\end{aligned}
$$

Berdasarkan hasil perhitungan dapat diketahui koefisien korelasinya yaitu : variabel minat belajar (X) dengan variabel hasil belajar Bahasa Indonesia (Y). Dari hasil pengolahan data diperoleh korelasi yang Kuat antara variabel minat belajar (X) dengan variabel hasil belajar Bahasa Indonesia (Y) sebesar 0,643 . Ini menunjukkan bahwa hasil prestasi murid pada mata pelajaran Bahasa Indonesia sangat baik.

Setelah koefisien korelasi $\left(\mathrm{r}_{\mathrm{xy}}\right)$ telah diketahui maka langkah selanjutnya yaitu melakukan uji hipotesis, pengujian hipotesis dilakukan agar dapat diketahui bahwa hipotesis yang diajukan dapat diterima atau ditolak. Untuk maksud tersebut teknik yang akan digunakan dalam pengujian ini adalah dengan menggunakan test signifikan yaitu membandingkan indeks korelasi anatara $\mathrm{r}_{\text {tabel }}\left(\mathrm{r}_{\mathrm{tb}}\right)$.

Untuk mengetahui apakah hipotesis yang digunakan diatas dapat diterima atau ditolak , maka berikut ini dilakukan pengujian sebagai berikut :

$$
\begin{aligned}
\text { Df } & =\mathrm{N}-2 \\
\mathrm{df} & =32-2 \\
& =30
\end{aligned}
$$

Dengan memeriksa tabel nilai "r" Product Moment dapat diketahui bahwa df sebesar 30 pada taraf signifikan $5 \%=0,361$ dan pada taraf signifikan $1 \%=0,463$.

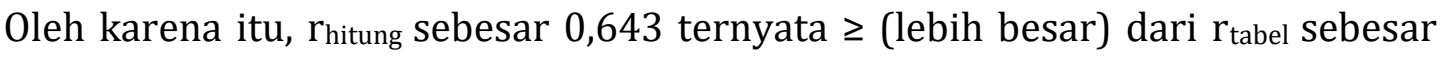
0,361 pada taraf signifikan $5 \%$ dan sebesar 0,463 pada taraf signifikan $1 \%$ maka hipotesis berbunyi :

“Terdapat Hubungan yang Kuat antara Minat Belajar dengan Hasil Belajar Murid pada Mata Pelajaran Bahasa Indonesia di SDN 4 Tg Batu Kecamatan Banggae Kabupaten Majene, dinyatakan "dapat diterima"

Berdasakan permasalahan penelitian dan kajian pustaka di atas, bahwa minat belajar Bahasa Indonesia dengan hasil belajar Bahasa Indonesia mempunyai hubungan yang kuat. Hal ini dibuktikan dengan hasil penelitian penulis dari hasil angket dan hasil belajar Bahasa Indonesia. Dari hasil angket, jumlah murid yang menjawab tinggi dalam minat belajar Bahasa Indonesia sebanyak 28,12 \% dibandingkan dengan jumlah 
murid yang menjawab sangat rendah yakni 9,38 \%. Hal tersebut juga dibuktikan melalui beberapa pengujian analisis.

Hasil analisis data menunjukkan bahwa Hubungan minat belajar Bahasa Indonesia (X), dan hasil belajar Bahasa Indonesia (Y) yang ditunjukkan dengan nilai koefisien korelasi sebesar 0,643. Sedangkan untuk uji signifikan uji r diperoleh bahwa

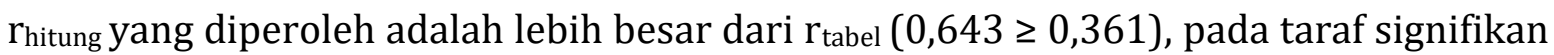
$5 \%$. Sehingga terlihat bahwa nilai $r_{\text {hitung }}$ lebih besar dari pada nilai $r_{\text {tabel }}$, maka hipotesis dalam penelitian ini "diterima" dan Terdapat Hubungan yang signifikan antara Minat Belajar dengan Hasil Belajar Murid dalam Mata Pelajaran Bahasa Indonesia Murid SDN 4 Tg Batu Kecamatan Banggae Kabupaten Majene.

\section{SIMPULAN DAN SARAN}

Berdasarkan hasil penelitian yang dilakukan tentang pengembangan model pembelajaran Predict, Observe, Discuss, dan Explain (PODE) untuk mata pelajaran IPA di SDN Kompleks IKIP Makassar, maka dapat disimpulkan: (1) Terdapat Hubungan yang signifikan antara Minat Belajar dengan Hasil Belajar murid dalam mata pelajaran Bahasa Indonesia murid SDN 4 Tg Batu Kecamatan Banggae Kabupaten Majene dengan koefisien sebesar 0,643. Artinya, Interval koefisien sebesar $\pm 0,60-0,799$ terdapat pada tingkat hubungan yang Kuat. (2) Minat belajar Bahasa Indonesia dengan hasil belajar Bahasa Indonesia mempunyai hubungan yang kuat. Hal ini dibuktikan dengan hasil penelitian penulis dari hasil angket dan hasil belajar Bahasa Indonesia. Dari hasil angket, jumlah murid yang menjawab tinggi dalam minat belajar Bahasa Indonesia sebanyak 28,12 \% dibandingkan dengan jumlah murid yang menjawab sangat rendah yakni 9,38\%. Hal tersebut juga dibuktikan melalui beberapa pengujian analisis.

Saran yang dapat diberikan: (1) Hendaknya murid meningkatkan minat belajarnya dengan cara berusaha aktif dalam kegiatan pembelajaran Bahasa Indonesia serta melakukan kegiatan - kegiatan yang berhubungan dengan mata pelajaran tersebut seperti menegerjakan PR dan mendengarkan penjelasan guru. (2) Guru diharapkan dapat menggunakan strategi pembelajaran yang menarik dan bervariasi pada pelajaran Bahasa Indonesia baik metode maupun media, sehingga murid tertarik dalam mengikuti pelajaran Bahasa Indonesia. (3) Peneliti selanjutnya disarankan untuk meneliti lebih mendalam tentang faktor yang dapat mempengaruhi hasil belajar 
murid dengan menambahkan faktor - faktor selain minat belajar dan hasil belajar murid.

\section{DAFTAR PUSTAKA}

Asfar. 2011. Pengaruh Minat Belajar Matematika, Motivasi Berprestasi, dan Kecerdasan Emosional terhadap Hasil Belajar Matemtika Murid Kelas X SMA Negeri di Kecamatan Sinjai. Skripsi. Makassar. UNM.

Azwar, Saifuddin. 2011. Penyusunan Skala psikologi, edisi kedua. Yogyakarta: Pustaka Pelajar.

Daryanto. 2009. Panduan Proses Pembelajaran Kreatif \& Inovatif. Jakarta: Av Publisher.

Ernawati. 2013. Pengaruh Kecerdasan Emosional, MInat Belajar, dan Gaya Kognitif terhadap Prestasi Belajar Matematika Murid Kelas X Tata Busana SMK Negeri Di Kabupaten Jeneponto. Tesis. PPs UNM.

Haling, Abdul. 2007. Belajar dan Pembelajaran. Makassar: Badan Penerbit UNM.

Hamalik, Oemar. 2008.Perencanaan Pengajaran Berdasarkan Pendekatan Sistem. Jakarta: Bumi Aksara.

Hartono, 2006. Peningkatan Hasil Belajar Matematika Melalui Pendekatan Pembelajaran Aktif, Kreatif, Efektif dan Menyenangkan Pada Murid Kelas VIII SMP Negeri 26 Makassar. Skripsi Universitas Muhammadiyah Makassar.

Ihsan, Muhammad. 2013. Pengaruh Metakognisi dan Motivasi Belajar terhadap Kemampuan Pemecahan Masalah Matematika melalui Kreativitas Belajar Murid Kelas VIII SMP Negeri di Kecamatan Kindang Kabupaten Bulukumba. Tesis. PPs UNM.

Kaniyem. 2010. Minat Belajar untuk Meningkatkan Prestasi Belajar Murid (Online). http://kaniyem.blog.uns.ac.id/2010/07/01/minat-belajar/.

Diakses, 28 juni 2016.

Muhammad \& Weheed. 2011. Secondary Student's Attitude Towars Mathematics in a Selected School Malderis. Journal (Online). International Journal of Humanities and Social Vol. 1 No 15 [Special Issue-October 2011] (Online). http://www.ijhssnet.com/journals.Vol_1_No_15Special_Issue_October_2011/3 4.pdf. Diakses, 28 juni 2016.

Murtafiah.2013.Pengaruh Kecerdasan Emosional, Pola Asuh Orang Tua, dan Minat Belajar terhadap Prestasi Belajar Matematika Murid Kelas XI IPA SMAN Di Kota Pare-Pare. Tesis. PPs UNM.

Padmono. 2002. Evaluasi dan Pengajaran. Surakarta: FKIP UNS. 
Ratumanan. 2004. Belajar dan Pembelajaran. Ambon: Unesa University Press.

Safari. 2003. Evaluasi Pembelajaran. Jakarta: Departemen Pendidikan Nasional Direktorat Jenderal Pendidikan Dasar dan Menengah Direktorat Tenaga Kependidikan.

Sagala, Syaiful. 2013. Kemampuan Profesional Guru dan Tenaga Kependidikan. Bandung: Alfabeta.

Sugiyono. 2011. Metode Penelitian Kuantitatif Kualitatif dan R \& D. Bandung: Alfabeta

Sahabuddin. 2007. Mengajar dan Belajar. Makassar: Badan Penerbit UNM.

Santrock, John. 2011. Psikologi Pendidikan Edisi Kedua. Jakarta: Kencana.

Schunk, Dale H. 2012. Motivasi dalam Pendidikan Teori, Penelitian dan Aplikasi. Jakarta: PT. Indeks

Soemanto. Wasty. 2003. Psokoligi Pendidikan: Landasan Kerja Pemimpin Pendidikan.Jakarta:Rineka Cipta

Sukardi. 2003. Metodologi Penelitian Pendidikan. Yogyakarta: PT Bumi Aksara.

Slameto. 2010. Belajar dan Faktor-Faktor yang Mempengaruhinya. Edisi Revisi. Jakarta: Rineka Cipta. 